\title{
LITERATURA E SEXUALIDADEA OU A RELAÇÃO ENTRE ARTE E DESEJO EM E. M. FORSTER
}

José Ailson Lemos de Souza*

RESUMO: A longevidade de E. M. Forster e o abandono precoce do romance, forma literária que o distinguiram como uma das vozes mais importantes da literatura inglesa no século XX, levantaram questionamentos sobre a influência da sexualidade em sua carreira. A publicação póstuma de Maurice (1971), que tornou evidente sua homossexualidade, fez surgir novas leituras de sua obra literária. Neste trabalho analisamos algumas questões relacionadas ao par literatura e sexualidade em textos não literários do autor como ensaios, palestras e crítica literária, com o fim de discutir o pensamento de Forster sobre a expressão do desejo sexual nas artes e as interdições e condicionamentos sociais decorrentes do contexto homofóbico em que viveu. Além disso, traçamos alguns paralelos entre essa discussão crítica do autor com a obra literária. Antes ainda, fazemos uma consideração breve sobre o termo sexualidade inserida no contexto regulatório que surgiu.

PALAVRAS-CHAVE: E. M. Forster; Literatura; Sexualidade.

\section{Introdução}

Há dois intervalos na trajetória literária mais conhecida de E. M. Forster (18791970). Após o período fecundo em que publicou a maioria de seus romances, Where Angels Fear to Tread (1905), A mais longa jornada (1907), Um quarto com vista (1908), e Howards End (1910), Forster precisou de mais de uma década para finalizar e publicar Passagem para a Índia (1924), talvez seu romance mais conhecido.

Após este último trabalho, o silêncio do romancista foi quebrado raras vezes na ficção, através de contos despretensiosos que pareciam confirmar o esgotamento de sua

\footnotetext{
* Doutorando em Literatura e Cultura pela Universidade Federal da Bahia (Ufba). Mestre em Literatura Comparada pela Universidade Federal do Ceará (UFC).
} 
capacidade criativa. Especulava-se que, enquanto romancista, Forster parecia incapaz de ir além da exploração de enfrentamentos individuais de membros da classe média inglesa, cujas aspirações pessoais se opunham aos códigos morais então vigentes, no período anterior à Segunda Guerra Mundial. Essas tensões repetiam-se nos romances, nas intermediações entre diferenças de classe social, cultural, ou racial, como no último romance publicado em vida. Assim, aparentemente, não restaria motivações para que o autor continuasse a repetir a fórmula.

Em Where Angels Fear to Tread e Um quarto com vista, o desejo sexual feminino aflora em terra estrangeira, na Itália, e o confronto deste com a xenofobia e o preconceito de classe ingleses tem desdobramentos trágicos no primeiro e cômicos no segundo romance. A independência financeira não isenta Helen Schlegel de prestar contas de seu comportamento sexual em Howards End. Já em Passagem para a Índia, os limites entre realidade e imaginação são suspensos justamente quando Adela Quested sofre, ou pensa ter sofrido, abuso sexual nas cavernas de Barabar. No mesmo romance, também fica em suspenso a atração entre Dr. Aziz e o professor Fielding. Em A Mais longa jornada, Rickie Elliot de certa forma reflete a frustração de Forster quanto ao conflitante entroncamento entre respeitabilidade e desejo homoerótico, tanto a nível pessoal quanto para a criação artística. Porém, a aparente falta de objetividade em abordar questões relacionadas ao sexo impacientavam leitores ilustres, como Katherine Mansfield, para quem Forster não conseguia ir além “do aquecimento do bule” (GARDNER, 2002, p. 162).

Com Maurice (1971), escrito entre 1913 e 1914, publicado postumamente, e revisado por George Steiner (2002, p. 476) como o romance menor de um autor importante, ocorre o desvelamento da sexualidade de Forster. Além da temática homossexual, o romance veio a público com uma nota exprimindo o objetivo maior do autor: viabilizar uma história de amor entre dois homems com final feliz, mesmo que essa realização fosse possível apenas na ficção. Com a nota, Forster alude aos efeitos da homofobia tanto nos círculos sociais em que viveu quanto na ficção, pois até então, convencionalmente, as narrativas que abordavam a homossexualidade haviam estabelecido o final trágico como padrão. 
Após Maurice, percebe-se uma tendência à revisão crítica da obra do autor. A divulgação pública da homossexualidade de Forster pesou não apenas para desqualificar Maurice, mediante alegações sobre a psicologia rasa dos personagens e um "constrangedor" recurso à sentimentalidade para tratar de relações homossexuais, como fizera Steiner, mas intensificou os questionamentos sobre a relevância literária de Forster. Como bem salienta John Herbert (2012, p. 211), a homofobia velada oriunda da crítica acadêmica acompanha a trajetória de Forster desde o início da carreira, muitas vezes relacionando homossexualidade com falha literária.

Além do mais, a orientação sexual de Forster parecia explicar a aporia literária que viveu. Elizabeth Heine (1984, p. 292) observa que Forster considerava a sexualidade um aspecto de pouco relevo para a análise literária. Entretanto, tal elemento tornou-se um fator de virada para sua fortuna crítica, fato revelador da importância cultural da sexualidade na modernidade. E mesmo que o autor estimulasse a desvinculação entre literatura e sexualidade na discussão crítica, seus textos de não ficção aludem à frustração que esse vínculo significava para ele.

Christopher Lane (2010, p. 117) pondera sobre a revisão do corpus crítico de Forster logo após sua morte. Formou-se então algumas concepções problemáticas, surgidas no calor do momento de revelação da orientação sexual do autor e que carecem de aprofundamento. Por exemplo, pensar que os enredos de casamento em Forster seriam tentativas frustradas de representar formas alternativas de amor. Ou ainda, que tais enredos, fundamentados em relações heterossexuais, estivessem além da capacidade do autor em representá-los. Além disso, no universo literário de Forster, a mulher seria representada de forma desfavorável em função de ser parte de uma tentativa malsucedida de compor um tipo de relação "ainda irrepresentável”, aquela entre homens. Lane alega que a insistência em correspondências entre a sexualidade do autor e seus romances, nesses termos, retiram por completo a fantasia - conceito-chave em grande parte da obra crítica e literária de Forster - e a imaginação, além de também desconsiderar as dificuldades estilísticas caras aos primórdios do modernismo. 
Para Lane (2010), o desejo sexual na ficção de Forster torna-se nebuloso, difícil de compreender, pois em diversos textos, o autor prepara um quadro favorável ao desejo enquanto dispositivo de libertação dos personagens, para em seguida surpreender o leitor com a frustração do desejo, e consequentemente da liberdade dos condicionamentos morais burgueses. Lane ilustra essa tendência através de narrativas que perfazem toda a trajetória literária de Forster, como o conto “The Story of a Panic", publicado no início da carreira, além de "The Other Boat" e "The Life to Come", publicados postumamente. Para Lane, com Maurice Forster supera essa frustração de expectativas, traço da repressão da época e de autocensura, e finalmente permite que o erotismo se realize (LANE, 2010, p. 113). Para o crítico, apesar de tornar célebre o lema "Ligue, simplesmente, a prosa e a paixão", presente em Howards End (1910), a obra do autor como um todo apresentaria as falhas inerentes ao ato de tentar estabelecer essa ligação. Os efeitos da sexualidade seriam deslocados, remodelados, e dissipados em novas formas, como a que Forster denominava por "afeto democrático" (democratic affection), que seria o desejo livre do apelo sexual.

Entretanto, o próprio texto de Lane indica uma diversidade de dilemas e resoluções no que concerne à sexualidade na ficção de Forster que inviabiliza assentir para tal leitura. Ao contrário do que defende Lane, de que os textos de Forster indicam uma dissociação entre sexualidade e autorrealização (LANE, 2010, p. 117), romances como Um Quarto com Vista e Maurice encenam justamente a reciprocidade necessária entre os termos.

George Steiner (2002), em resenha sobre Maurice publicada em 1971, alinha-se às opiniões da crítica de então: o texto escrito no início do século XX, ao vir a público, já estaria datado. Em estilo e complexidade, o romance destoaria de obras prestigiadas na década de 1970. Maurice passa a circular em uma época afeita ao legado literário de Ernest Hemingway. Porém, o crítico ressalta a importância de se conhecer a obra e situá-la no conjunto de romances do autor: "Maurice não é de modo algum o melhor de Forster. Porém, porque Forster é um escritor importante, com um trabalho coerente, esse romance póstumo força-nos a repensar sobre o conjunto de sua obra. Ele lança luzes específicas 
sobre o gênio de Passagem para a Índia"1 (STEINER, 2002, p. 476).

David Hugh (1997, p. 38), no entanto, afirma que com Maurice Hall, Forster concebeu o primeiro herói homossexual convincente da literatura no século XX. A diferença nas leituras de Steiner e Hugh resulta da mudança de paradigmas trazida pela Teoria Queer, que reconsidera textos e discursos contextualizando-os no escopo mais amplo de forças sociais, "identificações" e representações de relações homossexuais na literatura.

Os desdobramentos que um romance de temática homossexual tiveram para a crítica de Forster evidenciam uma dialética que opõe sexualidade e literatura, fornecendo uma boa oportunidade para pensarmos sobre o atrito entre a literatura sancionada e a proscrita, modalidades recíprocas e indispensáveis, que, nas palavras de Antonio Candido (2011, p. 177), comunicam um antagonismo entre os poderes e a resistência ao "estado de coisas predominante".

Se o contraste entre a carreira de romancista, cujo termo ainda na década de 1920 com Passagem para a Índia, e a longevidade de Forster, morto em 1970, indica um recolhimento, observa-se em Forster a problematização de questões relacionadas ao par literatura e sexualidade em outras formas e gêneros de expressão, como ensaios, palestras e crítica literária. A seguir, abordamos alguns desses textos com o objetivo de discutir o pensamento do autor sobre a expressão do desejo sexual nas artes e as interdições e condicionamentos decorrentes do contexto homofóbico em que viveu, sem deixar, sempre que possível, de traçar paralelos com a obra literária. Antes disso, discorremos sobre a sexualidade inserida no contexto regulatório que surgiu enquanto termo, determinante para demarcar identidades, "patologizar" indivíduos, e ao mesmo tempo, seguindo o pensamento de Judith Butler (1993), materializá-los.

\footnotetext{
${ }^{1}$ Maurice is not anywhere Forster's best. But because Forster is an important writer with a coherent oeuvre, this posthumous novel forces one to rethink his achievement as a whole. It throws particular light on the genius of 'A Passage to India'. (Obs: As traduções ao longo do texto são de minha autoria).
} 


\section{Sexualidade}

Temas envoltos ou em torno de questões da sexualidade permeiam a literatura desde os primórdios, mesmo que sexualidade seja um conceito relativamente recente. Joseph Bristow (1997/2001) apresenta o termo ressaltando a lacuna sempre presente entre a experiência erótica e a categoria utilizada para expressá-la. Bristow acompanha o pensamento de Jeffrey Weeks (1986), e compreende a sexualidade como "unidade ficcional", historicamente contingente, que veio à tona no momento em que o desejo sexual prestou-se para classificar, determinar, e até mesmo produzir novos desejos (BRISTOW, 2001, p. 5). O termo brota numa área do conhecimento também recente, a sexologia, que surgiu no final do século XIX com o fim de investigar as identidades sexuais (bissexual, homossexual, heterossexual, e variações) e práticas decorrentes do desejo sexual (fetichismo, sadismo, masoquismo, dentre várias) subsistindo por décadas a forte tendência a patologizar desejos e práticas que escapassem aos rígidos códigos de conduta vitorianos. Neste período, à medida em que surgem múltiplas "perversões”, o casal heterosexual, sob o escrutínio rigoroso da moral vitoriana, passou a ser a norma a regular a sexualidade (FOUCAULT, 1978, p. 38).

Estudos como Sexual Inversion (1897), de Havelock Ellis e John Symonds, tiveram o papel de revelar um tipo de desejo que colocava em debate a ideia de que o ato sexual teria como finalidade única a procriação, e como argumenta Bristow (2001, p. 14), apresentavam descobertas que setores conservadores da sociedade moderna se recusavam a conhecer. É curioso o surgimento de textos como esse no contexto britânico, pois era relativamente recente a criminalização de atos sexuais entre pessoas do mesmo sexo, lei que passou a vigorar em 1885 através do Criminal Law Amendment Act, contando com Oscar Wilde entre um de seus réus ilustres. Tanto o livro de Ellis e Symonds, de tendência liberal, quanto diversos outros que acentuavam a visão conservadora da época sobre sexo, foram banidos por simplesmente levantar a discussão em torno do tema.

Durante a vigência dos códigos morais vitorianos no século XIX, caracterizados pela rigidez e hipocrisia, a sexologia, sob a influência de campos diversos do saber, inicia a 
produção de crenças ancoradas em noções essencialistas. Tem início, segundo Jeffrey Weeks (2000, p. 46), uma "configuração de poder que exige classificar uma pessoa pela definição de sua verdadeira identidade". Dentro dessa nova configuração, a sexualidade passa a exercer um papel fundamental para o controle dos indivíduos. Weeks percorre as análises de Foucault sobre o biopoder, e destaca que o controle comportamental da população concentrou-se em quatro unidades: "a sexualidade das mulheres; a sexualidade das crianças; o controle procriativo; e a demarcação de perversões sexuais como problemas de patologia individual", tendo como resultado o surgimento de quatro figuras submetidas à observação e ao controle: "a mulher histérica; a criança masturbadora; o casal que utiliza formas artificiais de controle de natalidade; e o pervertido, especialmente o homossexual" (WEEKS, 2000, p. 47). Como desdobramento de processos sociais e históricos, portanto, a aceitação de alguns grupos de indivíduos e a marginalização e perseguição de outros passou a ser objeto de análises que percebem a sexualidade como construto cultural.

O acirramento entre a disseminação e a interdição dos discursos relacionados ao sexo, para Michel Foucault (1978) não passa de uma estratégia para transformar e estabelecer o sexo como discurso, incitando-o de modo a implantar, enquanto discurso, sexualidades polimórficas, heterogêneas. Foucault refuta a hipótese repressiva, de que a discussão sobre o sexo seria silenciada pelos dispositivos de poder, e identifica na realidade o engajamento do sexo como um dos modos de atuação do poder na sociedade. Nesse contexto, o filósofo francês vislumbra o nascimento de uma nova espécie, o homossexual. Se havia antes formas de criminalizar o ato sexual entre pessoas do mesmo sexo, é somente no século XIX que esse tipo de infrator passa à categoria de homossexual, "um personagem, um passado, um caso histórico, e uma infância, além de ser um tipo de vida, uma forma, com uma anatomia indiscreta e possivelmente uma fisiologia misteriosa. Toda a sua composição diz respeito à sua sexualidade"2 (FOUCAULT, 1978, p. 43). Articula-se,

${ }^{2}$ The nineteenth-century homosexual became a personage, a past, a case history, and a childhood, in addition to being a type of life, a life form, and a morphology, with an indiscreet anatomy and possibly a mysterious physiology. Nothing that went into his total composition was unaffected by his sexuality. 
portanto, séries relacionais que se embaraçam e se confundem, por exemplo, entre o que é íntimo e o que é social no campo das representações. O caso de Forster ter na própria sexualidade um elemento de reviravolta na interpretação de sua obra ilustra bem tal articulação.

Apesar de haver uma série de trabalhos importantes que bem situaram uma distinção entre sexualidade e gênero, tendo o primeiro campo absorvido discussões em torno da homossexualidade, e da opressão que a acompanha na forma da homofobia, Eve Sedgwick (1990, p. 27) afirma que sexo, gênero e sexualidade permanecem como termos escorregadios devido à relação que mantêm entre si. Acompanhando os desdobramentos das visões sobre sexo e gênero para a discussão teórica, Sedgwick (1990) parte de alguns pressupostos, como o que marcaria o sexo em torno das diferenças biológicas (formação genital, disposição da gordura corporal, distribuição de pêlos, funções hormonais, e capacidade reprodutiva) que distinguem membros da espécie humana entre os que apresentam pares de cromossomos XX daqueles que apresentam XY, ao passo que gênero seria um modo mais elaborado de separar dicotomicamente as identidades e comportamentos masculinos e femininos, com base em convenções culturais, mutáveis e variáveis, altamente relacional (o feminino seria definido primariamente em relação ao masculino), e estaria irremediavelmente atrelado ao histórico de poder entre os gêneros (SEDGWICK, 1990, p. 28).

Apesar dessa distinção, aparentemente simples, a autora afirma que os termos apresentam um histórico de usos que indicam sobreposições entre si, levando alguns a pensar em questões do sexo, ou da sexualidade, a partir de mapeamentos definidos pelo pensamento feminista, na distinção que este pensamento faz entre sexo e gênero. $\mathrm{Na}$ contramão deste pensamento, Sedgwick (1990) acredita que a sexualidade, mais do que o gênero, orienta uma compreensão sobre aspectos relacionais, sociais e simbólicos, de construção, e de representação do espaço em que o sistema sexo/gênero se situa. Segundo a autora, a prioridade pelo trato com a sexualidade deve-se ao fato de que ela

permeia todo o mapa empírico e conceitual da experiência e registra menos a solução de um problema do que uma escolha necessária de 
paradigmas analíticos [...] é verdadeiro para algumas instituições e visões correntes que sexo/sexualidade tende a representar um quadro completo de posições entre o mais íntimo e o mais social, o mais predeterminado e o mais aleatório, o mais fisicamente enraizado e o mais simbolicamente inculcado, o mais inato e o mais adquirido, o mais autônomo e o mais relacional traços do $\mathrm{ser}^{3}$ (SEDGWICK, 1990, p. 29).

Sedgwick acompanha a indicação de Gayle Rubin (1984/1993) sobre a necessidade de se distinguir entre sexo e gênero, do mesmo modo que gênero e classe, ou que classe e raça são diferenciados, os quais, apesar de enredados, não são a mesma coisa. Rubin propõe uma teoria do sexo que identifique, descreva, explique e denuncie o que chama de "injustiça erótica” e opressão sexual (RUBIN, 1993, p. 149). Para isso, torna-se necessária a análise da sexualidade como é vivenciada em sociedade e articulada pela história. As dificuldades para essa análise, segundo Rubin, foram sedimentadas pela tradição cristã, que sempre considerou práticas sexuais como forças negativas e destrutivas, principalmente quando retiradas dos contextos do casamento, da reprodução, e da experiência amorosa (RUBIN, 1993, p. 150). Rubin e Sedgwick percebem que o pensamento feminista tratava a sexualidade como um desdobramento de questões de gênero. Rubin (1993) cita como exemplo desta perspectiva o entendimento, por parte da chamada "ideologia lésbica", de que a opressão vivida por lésbicas poderia ser expressa nos termos do jugo que oprime as mulheres, quando na realidade, as lésbicas seriam alvo dos mesmos vetores de opressão que marginalizam, apagam e comumente aniquilam gays, sadomasoquistas, travestis, e prostitutas (RUBIN, 1993, p. 170). O pensamento feminista, de suma importância para a crítica da opressão de gênero, precisaria, segundo Rubin, reconhecer as dimensões políticas da vida erótica.

${ }^{3}[\ldots]$ something legitimately called sex or sexuality is all over the experiential and conceptual map is to record a problem less resolvable than a necessary choice of analytic paradigms or a determinate slippage of semantic meaning; it is rather, I would say, true to quite a range of contemporary worldviews and institutions to find that sex/sexuality tend to represent the full spectrum of positions between the most intimate and the most social, the most predetermined and the most aleatory, the most physically rooted and the most symbolically infused, the most innate and the most learned, the most autonomous and the most relational traits of being. 
A discussão sobre a sexualidade na obra de Foucault, evidenciando como os códigos e as identidades atuam em meio aos mecanismos de poder vigentes, tem sido aproveitada, desdobrada e expandida em explorações críticas diversas em áreas como os estudos culturais, de gênero, os estudos queer e os mais variados trânsitos teóricos e interdisciplinares. Between Men: English Literature and Male Homosocial Desire (1985/2010), estudo de Eve Sedgwick, por exemplo, propõe-se a analisar um período da cultura inglesa, através de sua literatura, entre a metade do século XVIII e a metade do século seguinte, por perceber nesse momento mudanças na estrutura de relações entre os homens, sejam relações de amizade, aprendizagem, rivalidade, de direito legal, ou hetero e homossexual, intrinsecamente relacionadas a mudanças nas relações de classe.

Sedgwick resume, em sua introdução, o entretecimento de relações de família, gênero, idade, classe e raça na instituição da sociedade patriarcal, "obrigatoriamente heterossexual" e homofóbica, características que não podem ser alteradas sem que se mude também as estruturas econômica e política (SEDGWICK, 2010, p. 2469). Essa característica conduz à dicotomia entre homossociabilidade e homossexualidade entre homens, ao passo que entre as mulheres os termos tendem para uma relação de continuidade. Assim, entre mulheres, o cuidado com os seus interesses geralmente não resvala quando se tratam de indivíduos que expressam desejo pelo mesmo sexo, como acontece entre homens.

Sedgwick argumenta que a solidariedade masculina, os interesses em comum, ou aspecto homossocial, que fundamenta o patriarcado, opõe-se ao desejo homossexual, uma vez que o casamento heterossexual caracteriza a instituição. Decorre disso, como percebe Gayle Rubin, citada por Sedgwick, que a opressão de homossexuais é gerada pelos mesmos mecanismos que oprimem as mulheres. Porém, segundo Rubin, o viés violento deste arranjo estrutural tem para os homossexuais um legado histórico comparável a um genocídio. 


\section{Sexualidade e desejo na obra literária e crítica de E. M. Forster}

Em "Sobre pornografia e sentimentalidade", texto de uma palestra consideravelmente curta, Forster (1920/2008) toca em questões pertinentes sobre a influência do desejo para a criação estética. Um de seus pontos de discussão é sobre a influência do sexo sobre a arte. Em que medida o sexo afeta, perturba o processo de criação de uma obra? Para o autor, uma obra despertaria dois prazeres distintos: o estético, viabilizado pelas formas (cores, traços, composição) e o sentimental, acessado pelos sentidos através dos conteúdos. Em sua exposição, Forster pretende entrar na polêmica sobre o status artístico da pornografia. Ou seja, um conteúdo cujo efeito primeiro seria a excitação física a partir da exposição de outros corpos poderia ser considerado arte? Forster escapa da controvérsia através da própria indefinição do que exatamente seria arte. Ele, porém, não deixa de comentar sobre a inexorabilidade do apelo carnal: “Todos nós desenvolvemos um ideal sexual, que também é espiritual, em certo sentido, pois nunca o encontraremos na terra, mas que é carnal em outro, uma vez que é preenchido com pensamentos libidinosos"4 (FORSTER, 2008, p. 54).

O artista teria a opção de ocultar esse apelo ou trazê-lo à luz. No caso de optar pela exposição, o artista seria compreendido apenas por aqueles que dividem semelhante "visão sexual". Subentende-se que as reservas ou a censura ao tratamento do sexo nas artes resultam de falhas no ato de compreender ou de identificar-se. Este, para se efetuar, necessita de uma relação de contiguidade entre a visão dos indivíduos. Se por um lado, essa disposição parece limitadora, por outro, ela teria como característica o despertar de dois prazeres (joys): o da companhia, ou camaradagem, obtido através da identificação, e o da fruição, no sentido de materializar um objeto de desejo (FORSTER, 2008, p. 55). Forster claramente discorre sobre a estimulação dos sentidos, processo que aproxima o artista do pornógrafo - ambos são “sentimentais”. Por sentimental, Forster relaciona o domínio das

${ }^{4}$ We all develop a sexual ideal as we grow up - an ideal that is spiritual in one sense for we shall never find it on the earth, but carnal in another for it may fill us with lustful thoughts [...]. 
emoções com o conteúdo (subject matter), e contrasta-o com a apatia do prazer estético provido apenas através da forma (technical skill). O questionamento do autor encerra a crença de que rebaixar o sentimental em favor do esteticismo equivale ao rebaixamento do desejo. Um exemplo deste pensamento, transmutado na ficção de Forster, foi sintetizado com o personagem Cecil Vyse em Um Quarto com vista. Cecil personifica o esteticismo seco, insensível, e por isso incapaz de despertar interesse sexual.

Se forma e conteúdo foram por vezes objetos de disputa na contenda sobre as especificidades da arte literária, ao apresentar uma predileção pelo trato com o conteúdo, Forster caminha na contra-mão de seus contemporâneos que investiam em explorações formais. Esse caminho influiu consideravelmente na construção de sua fortuna crítica, que, segundo Mary Lago (2008, p. 9), relega o autor a uma posição secundária no meio literário, ou às "luzes médias" do modernismo. Em estudo sobre as dinâmicas da crítica de Forster, John Herbert (2012) identifica a sexualidade como um dos aspectos a ser considerado na exploração deliberada do romancista das margens do modernismo. Para ele, Forster demonstra, ao longo da carreira, interesse e engajamentos político e estilístico nas margens (HERBERT, 2012, p. 4). Isso significa que o romancista estaria mais alinhado com uma das diversas tendências do modernismo, no caso, aquela interessada pela "crise ontológica" do próprio movimento, do que com um momento de transição para o modernismo, que, de acordo com Herbert (2012), representa uma visão ainda bastante difundida, como se pode inferir em autores diversos como Betty Jay (1998), J. H. Stape (1998), e Pericles Lewis (2007).

A ligação entre emoções e conteúdo, e a reserva de Forster quanto à primazia das experimentações formais aproxima-se da vitalidade com que Mikhail Bakhtin (2010) entendia a relação entre vida e arte: a vida penetra na arte "em toda plenitude de seu peso axiológico: social, político, cognitivo ou outro que seja. A arte é rica, ela não é seca nem especializada" (BAKHTIN, 2010, p. 33). Para ele, o conteúdo é um elemento éticocognitivo, comunicável através da empatia que decorre do "acontecimento do ato (atopensamento, ato-ação, ato-sentimento, ato-desejo, etc.)" (BAKHTIN, 2010, p. 39). Ou seja, 
à exemplo de Forster, que percebe no conteúdo um elemento tão importante quanto a forma, pois seria a partir dele que se ativam os sentidos, o pensador russo também destaca o apelo sensível deste elemento através da empatia, que antecipa um processo de conhecimento. Para ambos, vale ressaltar, o conteúdo opera na obra de arte a partir de uma relação de inextrincabilidade com a forma. Eles articulam, na realidade, um contraponto à pouca atenção crítica e teórica que recebia o primeiro elemento, se comparado ao segundo.

A concepção de conteúdo em Bakhtin (2010) necessariamente retira a obra de seu isolamento estético com o fim de abranger aspectos sociais e históricos que envolvem a individualidade ética, pois, do contrário, cessa a ligação com a experiência, interrompendo com isso o processo de reconhecimento. Esse processo, passagem de um não saber para o saber, em Aristóteles (2000, p. 49), diferencia a fábula (imitação de ações) simples das complexas. Indica, portanto, uma elaboração da arte literária. O reconhecimento, assim como a peripécia, para o filósofo grego, será efetivo quando mobilizar os sentidos do público, característica próxima àquela que Forster concebe com o termo sentimental, produzindo, por exemplo, temor ou piedade.

Aspectos do Romance (2005) reúne uma série de palestras ministradas por Forster em Cambridge e que por décadas influenciou o pensamento crítico sobre alguns dos elementos constitutivos do gênero romanesco. No volume, os textos foram divididos entre os tópicos abordados pelo autor, apresentados nos seguintes termos: A história (The story), Pessoas (People), O enredo (The plot), Fantasia (Fantasy), Profecia (Prophecy), e Padrão e Ritmo (Pattern and Rhythm).

No primeiro tópico, Forster discute aspectos relacionados à narrativa, seu desenvolvimento na sequência temporal, à voz narrativa e aos diferentes tons de sua expressão. No segundo, o autor problematiza as distinções entre os indivíduos que habitam o mundo sensível, real, e aqueles que habitam a ficção, sendo a condição de "seres humanos" o vínculo enfocado, de ligação, responsável pela escolha do termo. Quanto ao enredo, terceiro tópico, Forster fala sobre a ação das "pessoas", que, diferentemente dos eventos que formam a história, enfatiza a questão da causalidade. Já fantasia pode ser 
entendida como uma "excrescência", uma vez que pode fazer parte do texto literário ou não, sem prejuízo para o status artístico do texto. No caso de manifestar-se, a fantasia ilumina todos os outros elementos da narrativas, como um facho de luz (FORSTER, 2005, p. 102). Ela representa um desafio extra ao leitor, podendo afetar a "suspensão da descrença", mecanismo expresso pelo poeta Samuel Taylor Coleridge para o pacto entre leitor e ficção. A fantasia pode colocar a referida "suspensão" em risco, por exemplo, através da introdução de "um deus, fantasma, anjo, animal, monstro, anão, ou feiticeira no cotidiano" ou pela "introdução do homem para fora de seus domínios como o futuro, o passado, o interior da terra, a quarta dimensão" (FORSTER, 2005, p. 106).

Quando bem articulada, a fantasia adquire a qualidade de "iluminação" para a experiência estética. A profecia, por seu turno, abarca problemas como o tom empregado pelo artista, que pode estar repleto de valores religiosos, como do Cristianismo, Budismo, ou dualismo (coexistência de dois princípios necessários, como o bem e o mal) ou ainda expressar a resistência a tais valores. Por último, por Padrão e Ritmo Forster discute os efeitos estéticos explorados a partir do enredo e com o auxílio dos personagens. O padrão enquanto efeito pode decorrer de um arranjo que visa a simetria, análogo ao elaborado na pintura, como o desenvolvimento de personagens unidos através de um tema, por exemplo. Já o ritmo expressa um efeito comparável ao musical, através da repetição com variação de um motivo, imagem ou frase ao logo da narrativa.

Destaco da crítica literária mais conhecida de Forster a passagem sobre "Pessoas" em que caracteriza a vida humana segundo cinco "fatos": nascimento, alimentação, sono, amor e morte (FORSTER, 2005, p. 57). Sobre como esses fatos calham para serem transmutados pela ficção, o autor equilibra-se entre a espirituosidade, beirando a pilhéria, e o pesar, um misto de frieza e resignação, quando toca no fato amoroso e sexo:

E por fim, o amor. Utilizo esta palavra célebre no sentido mais amplo e maçante que possui. Permitam-me em primeiro lugar ser bem seco e breve sobre o sexo. Alguns anos após o nascimento de um ser humano, ocorrem algumas mudanças, assim como em outros animais, mudanças as quais levam à união com outro ser humano, e à produção de mais seres humanos. $\mathrm{E}$ assim caminha a nossa raça. 
O sexo tem início antes da adolescência, e sobrevive à esterelidade; é de fato coetâneo às nossas vidas, apesar de que, na época da procriação, seus efeitos tornam-se mais nítidos para a sociedade. Além do sexo, existem outras emoções, que também se fortalecem com a maturidade: várias elevações de espírito como a afeição, a amizade, o patriotismo, o misticismo. [...] Sugiro apenas que tomemos por amor esse conjunto inteiro de emoções e que o consideremos como a quinta mais importante experiência que os seres humanos têm que passar ${ }^{5}$ (FORSTER, 2005, p. 59).

O sexo, como uma das experiências na esfera amorosa, é rapidamente abordado e posto como atividade mecânica, com o fim de perpetuar a espécie, visão que reflete com ironia, e nitidamente a contragosto, o pensamento da sociedade da época. Esta, afinal, discerne melhor a manifestação do sexo no período de vida fértil dos indivíduos. De modo que se esgote em poucas linhas, Forster resume o conhecimento que poderia ser comunicado em público, como quando o desejo sexual se manifesta primeiramente, até quando, e o momento em que se torna mais evidente. Ao lado de amizade, patriotismo, e misticismo (amor à Deus), o sexo perfaz o circuito amoroso. Ao ser posicionado como a quinta experiência humana mais importante, atrás do nascimento, alimentação, sono, e morte (ciclo vital de um indivíduo), o circuito amoroso parece ser pensado em dimensão oposta ao ciclo da natureza, como um componente da esfera cultural, uma vez que afeição, amizade, patriotismo, e misticismo não são experiências vitais para a perpetuação da espécie. O sexo é apresentado de forma fria e mecânica quando serve a fins de procriação, e Forster sugere situá-lo sob a mesma aba de experiências que permeiam valores culturalmente construídos e mantidos.

O avizinhamento do sexo com outras experiências, como amizade e patriotismo,

\footnotetext{
${ }^{5}$ And lastly, love. I am using this celebrated word in its widest and dullest sense. Let me be very dry and brief about sex in the first place. Some years after a human being is born, certain changes occur in it, as in other animals, which changes often lead to union with another human being, and to the production of more human beings. And our race goes on. Sex begins before adolescence, and survives sterility; it is indeed coeval with our lives, although at the mating age its effects are more obvious to society. And besides sex there are other emotions, also strengthening towards maturity: the various upliftings of the spirit, such as affection, friendship, patriotism, mysticism. [...] All I suggest is that we call the whole bundle of emotions love, and regard them as the fifth great experience through which human beings have to pass.
} 
ativa uma escala de valores que Forster trabalhou em trabalhos de ficção de não-ficção. Em Howards End (1910), por exemplo, a amizade é um tipo de relação tão central para Ruth Wilcox e Margaret Schlegel que sobrepuja os laços de sangue, quando a primeira decide legar para a amiga o único bem que possuía. No ensaio What I Believe (1938), Forster enfatiza a estima que nutria por relações pessoais ao afirmar que o amor e a lealdade entre amigos, para ele, sobrepõe-se ao patriotismo. Multifacetada, como toda forma de relação pessoal, a amizade foi tematizada por Forster e problematizada na tensão com o desejo sexual. Ou ainda, como um tipo de união entre dois indivíduos que é socialmente aceita. É o que se depreende da relação entre Stewart Ansell e Rickie Elliot em The Longest Journey (1907), entre o Dr. Aziz Ahmed e o professor Richard Fielding em Passagem para a Índia (1924) e entre Maurice Hall e Clive Durham, em Maurice (1914). Observa-se nos três romances espécies de experimentos quanto às possibilidades e desdobramentos para esse tipo de vínculo.

No primeiro e no último romance referidos acima, a ligação entre os amigos claramente apresenta elementos de atração sexual. Seja por falta de reciprocidade ou devido aos riscos ao status social dos personagens, a atração assoma como impasse, para em seguida ser frustrada. Em Passagem para a Índia, o desejo entre os personagens se mantém latente, uma sugestão em aberto que pode até mesmo passar despercebida.

David M. Halperin (1990, p. 75) identifica em Forster, precisamente em The Longest Journey, a compreensão de um tipo de laço, que, mesmo reconfigurado a partir do erotismo ou de ideais platônicos de amizade, produz um “autoconhecimento coletivo” viabilizado por princípios de classificação. Ou seja, expressa, a partir da relação com outro indivíduo, um reconhecimento público. A partir de uma passagem do romance de Forster, em que Rickie Elliot manifesta o desejo de ter sua amizade classificada por uma sociedade capaz de selar o casamento de "mentes verdadeiras", Halperin (1990) percebe no romancista uma continuidade estrutural com base nos vínculos entre dois homens, visando o reconhecimento público, e que remonta à antiguidade. A amizade entre Aquiles e Pátroclo na Ilíada, Gilgamesh e Enkidu na Epopéia de Gilgamesh, e Jônatas e Davi no texto bíblico de 
Samuel, é apresentada segundo os seguintes princípios: a amizade somente entre dois indivíduos do sexo masculino, formando um par sem rivais, sem relações com o sexo oposto que possa atrapalhar a amizade, e que, mesmo apresentando um viés sentimental, firma-se com o objetivo de obter reconhecimento social, através de atos gloriosos ou fins políticos (HALPERIN, 1990, p. 77).

O ressurgimento desse tipo de relação na obra de Forster talvez seja um obstáculo para compreender certos dilemas em torno da sexualidade, que, como se depreende de algumas leituras, a exemplo da que faz Christopher Lane (2010), sugere uma desvinculação entre afeição e desejo erótico com base na frustração do desejo, quando na realidade a obra do romancista pode ser vista como um mosaico de experimentos, de tentativas de realização pessoal através de algum tipo de união entre dois indivíduos. A amizade entre um herói e um homem comum que visa o reconhecimento público, para citar uma das peças do mosaico, pode ser lida em Maurice de modo que o arranjo identificado por Halperin é manipulado, alterando assim o objetivo da ligação entre os pares, como se pode observar a seguir:

[Alec] não recebera treinamento específico, mas tinha jeito para o críquete, e o jogo tornou a ficar sério. Maurice também jogou bem. Sua mente havia aclarado e sentiu como se estivessem jogando contra o mundo todo: não eram apenas o senhor Borenius e os jogadores, mas também as senhoras no abrigo e toda a Inglaterra, todos cerravam forças em torno dos wickets. Maurice e Alec jogavam um pelo outro, e em prol de seu frágil relacionamento - se um caísse o outro seria derrubado também. Não pretendiam causar nenhum mal ao mundo, mas, se ele os assaltasse, haveriam de castigá-lo, precisavam estar a postos e então atacar com toda a força, precisavam mostrar que, quando dois se juntam, as maiorias não triunfam (FORSTER, 2006, p. 205).

Se por um lado, o trecho transmite uma imagem romântica, de amantes unidos contra todo tipo de obstáculo, por outro ele curiosamente antecipa um dos lemas característicos do movimento queer, articulado originalmente em Londres e Nova York a partir da década de 1990: o Bash Back (literalmente, bater de volta). O reconhecimento público, ainda não viável no contexto representado, deixa de ter importância para Maurice e Alec a partir do momento que decidem se retirar da sociedade londrina para viverem 
juntos nos arredores de Londres. Tanto a atitude de contra-ataque dos amantes perante à sociedade quanto o desdém para o reconhecimento social podem ser compreendidos como elementos de fantasia articulados pelo autor de modo a projetar um futuro diferente daquele contexto representado tanto pela ficção quanto pela biografia de Forster.

\section{Considerações finais}

Numa das passagens mais inquietantes de Maurice, o protagonista procura ajuda para se livrar do desejo "inominável” que sente por outros homens, através da hipnose. O hipnotizador, Dr. Lasker Jones, após várias sessões, sugere que Maurice mude de país. Na França e na Itália, por exemplo, não era crime ser homossexual. Contudo, Maurice decide permanecer na Inglaterra, e retira-se da sociedade junto com Alec Sccuder. A possibilidade de publicar um romance como o de Forster, somente após 1967, veio acompanhada de uma lenta mas progressiva conquista de direitos, da luta dos movimentos gays, posteriormente LGBT, que ajudaram a transformar a Inglaterra atual num espaço mais igualitário, ao menos do ponto de vista sexual, do que aquele em que Forster viveu.

E é com espanto que escrevo essas palavras finais, ao perceber semelhanças entre aquele contexto autoritário e o nosso, em que uma exposição, o Queermuseu - Cartografias da diferença na arte brasileira, com curadoria de Gaudêncio Fidelis, foi cancelada em Porto Alegre sob alegações de fomentar a pedofilia e a pornografia, dentre outras “degenerações”. Como bem salienta Ivana Bentes, numa coluna para a Revista Cult, não bastou aos detratores da exposição simplesmente não irem prestigiar o trabalho de artistas como Leonilson, Portinari, Adriana Varejão, e Ligia Clark, dentre diversos nomes reconhecidamente importantes para as artes plásticas do país. O viés autoritário interveio com a proibição do direito do público de ter acesso às obras.

Tal retrocesso coloca em evidência a dimensão política tanto da arte quanto da vida erótica. Forster ousou comparar o artista ao pornógrafo, devido à capacidade de ambos de colocar em relevo setores da existência historicamente rebaixados, como a sexualidade, o apelo carnal, o desejo sexual, os quais têm servido como pretexto para negar e apagar o 
outro. Percebe-se também a pertinência do pensamento crítico de Forster e Bakhtin, que identificam no conteúdo - e o sexo é exemplar neste sentido - um elemento ligado ao sensível, à ética, bem como aos aspectos cognitivo e social. Interditar formas de expressão, no presente ou no passado, sob a justificativa de limitar aquilo que pode ou não ser arte, demonstra não só desconhecimento cultural, mas o uso arriscado de moralismos rasos para camuflar nossa faceta tirânica e opressora.

\title{
LITERATURE AND SEXUALITY OR THE RELATION BETWEEN ART AND DESIRE IN E. M. FORSTER
}

\begin{abstract}
E. M. Forster's longevity and his rather premature retirement from writing novels, for which he became known as one of the most distinguished voices of English literature in the 20th century, gave rise to speculations on the influence of his sexuality over his career. Maurice (1971), published posthumously, and which made his homosexuality evident, brought new readings of his works. In this study, we consider some questions related to literature and sexuality in Forster's non literary works, such as essays, public speeches and criticism, in order to discuss his thought over sexual desire as it is expressed in the arts, as well as the role of censorship and social conventions in the homophobic context in which he lived. we also draw some parallels between that discussion and his novels. Before that, we consider briefly the term sexuality in the regulatory context in which it emerged.
\end{abstract}

Keywords: E. M. Forster; Literature; Sexuality.

\section{REFERÊNCIAS}

ARISTÓTELES. Poética. Trad. Eudoro de Souza. São Paulo: Nova Cultural, 2000.

BAKHTIN, Mikhail. Questões de Literatura e de Estética: A Teoria do Romance. Trad. Aurora Bernardini e outros. São Paulo: Hucitec, 2010.

BENTES, Ivana. A arte que virou pornografia aos olhos dos neofundamentalistas. Revista Cult Online. Disponível em: https://revistacult.uol.com.br/home/arte-que-viroupornografia-aos-olhos-dos-neofundamentalistas/ Acesso: 13/09/2017.

BRISTOW, Joseph. Sexuality. New York: Routledge, 2001.

BUTLER, Judith. Bodies that matter: on the discursive limits of "sex". New York: Routledge, 1993.

CANDIDO, Antonio. O Direito à Literatura. In: . Vários Escritos. Rio de Janeiro: Ouro Sobre Azul, 2011. 
FORSTER, E. M. Aspects of the Novel. London: Penguin, 2005.

. On Pornography and Sentimentality. In: HEATH, J. F. The Creator as Critic: and other writings by E. M. Forster. Ontario/CA: Dundurn, 2008.

- What I believe (1938). Disponível em: http://www.skeptic.ca/EM_Forster _What_I_Believe.htm Acesso: abril de 2017.

. Maurice. London: Penguin, 2005.

. Howards End. London: Penguin, 2000.

. A Room with a View. New York: Dover, 1995.

. A Passage to India. London: Penguin, 2005.

. The Longest Journey. London: Penguin, 2001.

. Where Angels Fear to Tread. New York: Dover, 2011.

FOUCAULT, Michel. The History of Sexuality. Vol 1: An Introduction. Trad. Francês Robert Hurley. New York: Pantheon Books (Random House), 1978.

GARDNER, Phillip. (ed.) E. M. Forster: The Critical Heritage. London: Routledge, 2002.

HALPERIN, David M. One Hundred Years of Homosexuality: and other essays on Greek Love. New York: Routledge, 1990.

HEINE, Elizabeth. Afterword to The Longest Journey. In: FORSTER, E. M. The Longest Journey. London: Penguin, 2001.

HERBERT, John. A Revaluation of E. M. Forster's Fiction. Tese (Doutorado em Literatura Inglesa). University of Birmingham, 2012. Fonte: http://etheses.bham.ac.uk/4184/ Acesso: março de 2017.

HUGH, David. On Queer Street: A Social History of British Homosexuality. London: Harper Collins, 1997.

LAGO, Mary. Introduction. In: (ed.). The BBC Talks of E. M. Forster, 1929-1960. Columbia: University of Missouri Press, 2008.

LANE, Christopher. Forsterian sexuality. In: BRADSHAW, David. (ed.). The Cambridge Companion to E. M. Forster. Cambridge: Cambridge University Press, 2007.

RUBIN, Gayle. Thinking Sex: Notes for a Radical Theory of the Politics of Sexuality. In: ABELOVE, Henry. (ed.). The lesbian and gay studies reader. New York: Routledge: 1993.

SEDGWICK, Eve. K. Epistemology of the Closet. Los Angeles: University of California Press, 1990.

. Between Men. Introduction. In: LEITCH, Vincent B. (ed.) Norton Anthology of Theory 
and Criticism. New York: W. W. Norton and Company, 2010.

STEINER, George. Under the greenwood tree. In: GARDNER, Phillip. (ed.) E. M. Forster: The Critical Heritage. London: Routledge, 2002. p. 475-82.

WEEKS, Jeffrey. Sexuality. London: Tavistock, 1986.

. O corpo e a sexualidade. In: LOURO, Guacira L. O Corpo Educado. Trad. Tomaz Tadeu da Silva. Belo Horizonte: Autêntica, 2000.

Recebido em: 15/09/2017. Aprovado em: 13/11/2017. 